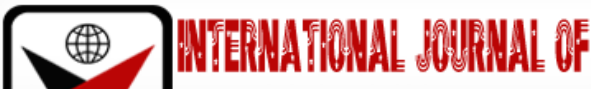

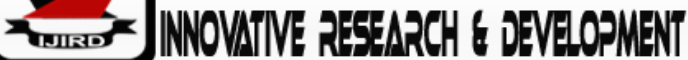

ISSN 2278 - 0211 (Online)

\section{Florence Nightingale's Environmental Theory and its Impact on Patients Health Case Study}

\author{
Faisal Nadeem \\ Principle, Rashid Latif Nursing College, Rashid Latif Medical Complex, Lahore, Pakistan
}

\begin{abstract}
:
Theoretical framework is the essence of nursing practice; it serves as an organizing paradigm for a body of knowledge. This manuscript will describe a clinical picture which was analyzed through Environmental Theory of Florence Nightingale; this theory comprises 13 environmental canons that are described in detail. The most important canons are; ventilation, light, noise, cleanliness of rooms/walls, bed and bedding, personal cleanliness, and taking food. She emphasizes the importance of modification of environmental canons to refurbish patient healthiness in the best natural ways. The same importance is reflected in the respected clinical picture. Therefore, a great need is felt to incorporate Nightingale's pioneer work that provides a base to practice nursing holistically even in this modern era. Following recommendations can be made from this scenario; (a) Improving hospital/house infrastructure with good ventilation and light (b) hospitals should be noiseless/smokeless (c) raising awareness regarding environmental hygiene at community level through mass media, community nurses and health visitors. Healthcare practices can be improved in developing countries by taking these measures.
\end{abstract}

Keywords: Florence nightingale, environmental theory, practical application at clinical area, theory and theory analysis

\section{Introduction of Environmental Theory}

Florence Nightingale was born on 12 May, 1820 in Florence, Italy. She was the founder of modern nursing as her role came to prominence during the Crimean War (1854) where she trained many junior nurses, cared many wounded soldiers, and recorded their data statistically. She was entitled "The Lady with the Lamp" because of her services in the Crimean War. Florence also established a hospital and a nursing school in London and in1859 she published her famous book "what it is and what it is not", these nursing notes were the foundation for research in nursing. Her 13 canon "Environmental Theory" is the best for theory for prevention, restoration and for the delivery of care.

Nursing, Person, Environment and Heath are the four meta-paradigms. According to the theory, a Person is a recipient of nursing care (Selanders, 2010) a good internal/external Environment helps to retain energy (Nightingale, 1860) and nursing helps in modification of environmental factors and a nurse enhances the ability of a person towards healing and improving a person's ability so that he/she should take care of himself(Whelan,1984)and Health which according to Florence nightingale is "Health is not only to be well, but to be able to use well every power we have" (Nightingale, 1860).

\section{Clinical Scenario}

Even today I memorize that winter evening when I met the most distressing situation of my routine work during my clinical practice. That day I was assigned in a primary health care center of Lahore, Pakistan. A 70 year old male patient came with his 2 sons having complaint of high grade fever (103F) with shivering chills. I observed that the patient have difficulty in breathing as patient preferred to sit in high fowler's position. I introduced myself and started dialogue with patient. However, I felt that he is in a state of apprehension and that was due to his dyspnea. I administered supplemental oxygen $2 \mathrm{~L} /$ minute. By occupation, my client was associated to labor. He was illiterate. His presenting complains was high grade fever (104 Fahrenheit) with shivering chills, productive cough and shortness of breath. Upon physical assessment I listened unilateral Crackles on chest auscultation.

He also complained chest pain while coughing. He was a known case of diabetes that was the cause of impaired skin integrity on his sacral region and reduced sensation on his toes. He had a femur fracture four month back that was corrected surgically. He was Hukka smoker for the past forty years. His wife died one year back. His son explained that his grand-daughter died due to pneumonia. They claimed that his health status is not good and it is only due to smoking Hukka otherwise he was quiet well. Halitosis, filthy dress and greasy hairs were a sign of poor hygiene.

According to attendant the patient was living in a small house with four sons. During my community visit I found that he lives in a mud house poorly ventilated due to absence of window and they don't have proper latrine. Furthermore, clean drinking water was a rare commodity for them. All that shows that he belongs to low socioeconomic status. In 
addition, the poor drainage system over that community was not up to the standard, there were no adequate lights and sunlight was not passing into the rooms, and they have to a single room with 4-5 persons.

\section{Case Analysis from the Perspective of Nightingale's Theory}

If we evaluate the clinical scenario from the lens of nightingale's theory we will come to know that why the condition of the patient got worsen and which factors added in exacerbation of the patient's condition.The patient reached to this condition because of the environmental factors and because of the absence of a community nurse. A nurse which focuses on the nursing meta-paradigms and using the good observatory and critical skills brings change in the condition of patients. In the above case, there was a need to change the physical environment of the patient for the prevention of the disease. Crowded room, unavailability of fresh air and poor ventilation and a pneumonic patient's death in family were the contributing factors towards the worsening condition of the patient.

Old age, smoking and infrastructure of the house were contributing factors which enhanced prone-ability of the patient's towards respiratory infection. Fresh air is very important for health and poor infrastructure of the home contradicts the entry of fresh air in home and the importance is also evident by Florence nightingale's notes "The very first canon of nursing, the first and the last thing upon which a nurse's attention must be the first essential to the patient, without which all the rest you can do for him is as nothing, with which I had almost said you may leave all the rest alone, is this: To keep the air he breathes as pure as the external air, without chilling him". (1960.p-8). She further explore that "No ventilation can freshen a room where the most scrupulous cleanliness is not observed. Unless the wind be blowing through the windows at the rate of twenty miles an hour, dusty carpets, dirty wainscots, musty curtains and furniture", (1960. P-87).

Infection prevention and its association to ventilation of fresh air is well emphasized by nightingale and because there were no windows in that poorly designed home of patient which prevented fresh air to come in. She says in her notes that "Always air your room, then, from the outside air, if possible. Windows are made to open; doors are made to shut-a truth which seems extremely difficult of apprehension". (1960. P-20).

Additionally, some other important factors like unhygienic and stale food, contaminated drinking water and inaccessible sunlight were some factors due to which the patient developed pneumonia. From the perspective of nightingale's theory "It ought to signify the proper use of fresh air, light, warmth, cleanliness, quiet, and the proper selection and administration of diet all at the least expense of vital power to the patient" (1960. p2-3)she also added that health care providers (nurses) are not solely responsible for mismanagements and said that "By this I do not mean that the nurse is always to blame. Bad sanitary, bad architectural, and bad administrative arrangements often make it impossible to nurse". (1960. p-3) so there may be a fault with the administration or the architecture personnel as well. Therefore, for disease prevention we need to understand the importance of good architecture for a well ventilated hospital and home and good administration to use the resources afterwards.

According to Florence nightingale, except good diet, exposure to sunlight, fresh air from fresh environment and fresh clean water, good personal hygiene, education regarding illness and wellness a focus must be on living environment of the patient as she said "Old papered walls of years' standing, dirty carpets, uncleansed furniture, are just already sources of impurity to the air as if there were adding-heap in the basement" (1960. P-27).

Florence nightingale also emphasized on the importance of bed and bedding. As the patient was operated in past so he needed a comfortable bed and changing of bed sheet on daily basis. Old patients are more prone to bed sores from poor conditioned bed mattresses and from bed sheets. As a widower he was unable to receive proper care in the form of positioning which was not possible as he was very old. Thus his skin was impaired due to long one position stay. Diabetes Mellitus also added in his worsening toe ulcer as in diabetes our sensation is lost and hardening of the blood vessels cause low blood supply to affected areas. Moreover, frequent changing of linen was needed because "If you consider that an adult in health exhales by not only the lungs and skin in the twenty-four hours three pints at least of moisture, loaded with organic matter ready to enter into putrefaction; that in sickness the quantity is often greatly increased, the quality is always more noxious just ask yourself next where does all this moisture go to? Chiefly into the bedding, because it cannot go anywhere else". (1960.p-80).

\section{Opportunistic Factors}

Some other factors contributed in the worsening condition of the patient. The patient was in a state of Self-care deficit due to poverty, age factor, illiteracy and because of the death of the spouse. Smoking decreases immunity, thus pneumonia was developed due to low immunity and got worsen due to some environmental factors such as poor ventilation and availability of fresh air. Poor hygienic condition and overcrowding in the living place were other contributing factors. Patient's surgery, diabetic neuropathy and poor understanding of the care takers about the importance of environmental and other factors were the leading factors and therefore the saying of Henderson defines this in a better way that "The unique function of nurses in caring for individuals, sick or well, is to assess their responses to their health status and to assist them in the performance of those activities contributing to health or recovery or to dignified death that they would perform unaided if they had the necessary strength, will, or knowledge and to do this in such a way as to help them gain full of partial independence as rapidly as possible" (Henderson, 1977, p.4).

\section{Hypothesis Derived from Environmental Theory to Test a Nursing Intervention}

In the above clinical scenario there was a possibility to change the unpleasant outcomes under the below mentioned hypothesis: 
- Under certain comorbidities and risk factors like old age, smoking, diabetes mellitus, weak immunity, low socioeconomic status, poor architecture and marital status there were chances of worse patient condition.

- If patient was adequately educated during discharge by a nurse it would have helped in reduction of impaired skin integrity.

- If the patient had a good understanding of diabetes mellitus and control over it can reduce the risk of peripheral neuropathy.

- If the patient had understanding of adequate ventilation and good hygiene then the patient might not get pneumonia.

- $\quad$ Better infrastructure and proper designed communities helps in reduction of infectious diseases. $6 . \quad$ Availability of Interventions like health education at community level by a community nurse about personal hygiene, food quality, bed and bedding if provided to the patient may had helped as a preventive measure.

\section{Conclusion}

Nursing theories revolve around the four (Environment, Person, Health, and Nursing) metaparadigms and among the four Florence nightingale focused on the environment. All others are equally important to understand for health care providers in the hospital and community settings. Diversely the environmental theory lenses through 13 important canons which a person need during illness and wellness. The registered nurses, nursing students and other health care providers may take help from the above discussed perspective to how to use and relate this theory in their practical life.

\section{Recommendations}

The environmental theory is applicable in all settings whether in-patient, out-patient as or community setting. The following recommendations if applied may improve patient outcomes;

- Incorporation of the theory in the curriculum of those associated with health care industry.

- Educational programs as a continuous process by a nurse at the community level.

- Clinical nursing instructors should emphasize the application of the theory by nursing staff and students during their routine work.

\section{References}

i. Nightingale, F. (1860). Notes on Nursing: what it is and what it is not. London; Harrison, 59, Pall mall, bookseller to the Queen.

ii. Selanders, L.C. (2010). The Power of Environmental Adaptation: Florence Nightingale's Original Theory for Nursing Practice. Journal of Holistic Nursing. (28) 81-88.

iii. Whelan, E. G. (1984). Analysis and application of Dorothea Orem's self-care practice model. Journal of Nursing Education, 23(8), 342-345. 